\title{
Fingerprint changes in CSF composition associated with different aetiologies in human neonatal hydrocephalus: glial proteins associated with cell damage and loss
}

Irum Naureen ${ }^{1,6}$, Khawaja A Irfan Waheed ${ }^{2}$, Ahsen W Rathore ${ }^{2}$, Suresh Victor ${ }^{3}$, Conor Mallucci ${ }^{4}$, John R Goodden ${ }^{5}$, Shahid N Chohan ${ }^{6}$ and Jaleel A Miyan ${ }^{1 *}$

\begin{abstract}
Background: In hydrocephalus an imbalance between production and absorption of cerebrospinal fluid (CSF) results in fluid accumulation, compression and stretching of the brain parenchyma. In addition, changes in CSF composition have a profound influence on the development and function of the brain and together, these can result in severe life-long neurological deficits. Brain damage or degenerative conditions can result in release of proteins expressed predominantly in neurons, astroglia, or oligodendroglia into the brain interstitial fluid, CSF and blood. Determination of such products in the CSF might be of value in diagnosing cause, aetiology and/or assessing the severity of the neurological damage in patients with hydrocephalus. We therefore analysed CSF from human neonates with hydrocephalus for these proteins to provide an insight into the pathophysiology associated with different aetiologies.

Methods: CSF was collected during routine lumbar puncture or ventricular tap. Samples were categorized according to age of onset of hydrocephalus and presumed cause (fetal-onset, late-onset, post-haemorrhagic or spina bifida with hydrocephalus). Glial fibrillary acidic protein (GFAP), myelin basic protein (MBP), vimentin and 2', 3'-cyclic nucleotide 3 -phosphodiesterase (CNPase) were analysed through Western blotting of hydrocephalic CSF samples $(n=17)$ and compared with data from CSF of normal infants without neurological deficits $(n=8)$.

Results: GFAP was significantly raised only in CSF from post-haemorrhagic hydrocephalus while MBP was significantly raised in post-haemorrhagic and in spina bifida with hydrocephalus infants. Vimentin protein was only detected in some CSF samples from infants with late-onset hydrocephalus but not from other conditions. Surprisingly, CNPase was found in all neonatal CSF samples, including normal and hydrocephalic groups, although it was reduced in infants with late onset hydrocephalus compared with normal and other hydrocephalic groups.

(Continued on next page)
\end{abstract}

\footnotetext{
* Correspondence: j.miyan@manchester.ac.uk

${ }^{1}$ Faculty of Life Sciences, The University of Manchester, AV Hill Building,

Oxford Road, Manchester M13 9PT, UK

Full list of author information is available at the end of the article
} 


\begin{abstract}
(Continued from previous page)
Conclusions: Apart from CNPase, which is an enzyme, the markers investigated are intracellular intermediate filaments and would be present in CSF only if the cells are compromised and the proteins released. Raised GFAP observed in post-haemorrhagic hydrocephalus must reflect damage to astrocytes and ependyma. Raised MBP in post-haemorrhagic and spina bifida with hydrocephalus indicates damage to oligodendrocytes and myelin. Vimentin protein detected in some of the late-onset hydrocephalic samples indicates damage to glial and other progenitors and suggests this condition affects periventricular regions. The presence of CNPase in all CSF samples was unexpected and indicates a possible novel role for this enzyme in brain development/myelination. Less CNPase in some cases of late-onset hydrocephalus could therefore indicate changes in myelination in these infants. This study demonstrates differential glial damage and loss in the developing human neonatal hydrocephalic brain associated with different aetiologies.
\end{abstract}

Keywords: Hydrocephalus, Human neonates, CSF, GFAP, Vimentin, CNPase, MBP

\section{Background}

Hydrocephalus is a pathological condition characterised by an abnormal production and/or absorption of cerebrospinal fluid (CSF). The aetiology of hydrocephalus is unclear, even with some evidence of genetic predisposition [1]. With a global incidence of 1:500 (NIH, USA), hydrocephalus affects between 1:100-1:5000 live human births with a lower incidence in developed countries achieved through elective terminations. Hydrocephalus can result in deficient/abnormal cerebral cortex development and lifelong neurological deficits [2-4]. The pathophysiology of hydrocephalus in neonates remains poorly understood since they do not experience raised intracranial pressure despite accumulation of CSF in the brain accompanied by ventricular and cranial expansion $[5,6]$. The extent of ventricular dilation depends on the location of CSF blockage and length of time of the block $[7,8]$. Fetal-onset ventriculomegally (enlarged ventricles without raised pressure) is thought to result in more severe brain damage $[3,4]$ but recent studies challenge this notion [9] even though ventricular expansion, and consequential compression and stretching of the brain must have a damaging effect in severe cases. Currently the only control measure is birth termination and the only treatment option is surgical fluid diversion. Although surgery does address the life-threatening raised intracranial pressure, compression and stretching of the brain parenchyma, it does not recover lost or abnormal development, cellular damage or the life-long neurological issues resulting from these [4-6].

Improvements in prenatal diagnosis and treatment will raise the quality of life for children with hydrocephalus through decreased mortality and morbidity, but this may only be through a better understanding of the underlying aetiology and biological basis of the condition and the development of additional treatments to shunt surgery. The literature in both human and experimental animal studies is not clear with controversy on cause and with much work targeted at understanding the consequences of raised pressure rather than possible earlier events, due in large part to the view of CSF as a mechanical support fluid rather than a fluid with physiological importance. The latter role of CSF is currently under considerable review and renewed research [10-13] with some new insights emerging into the unique part played by CSF in development and brain function $[9,14,15]$. Recent research has focused on the interplay between CSF signals and their role in normal neurodevelopment [11-13], and there is growing evidence that secreted proteins or other factors within the CSF have an age-dependent effect on neural cell precursor proliferation and cortical development [14]. Thus, major alterations in CSF protein composition in neonatal neurological disease states could have direct and significant effects on global neurodevelopment [16]. Alternatively an imbalance in the levels of specific CSF proteins may directly affect on-going neurodevelopmental processes, which could lead to the developmental defects associated with post-haemorrhagic hydrocephalus [17] as well as those already associated with CSF composition changes in fetal-onset hydrocephalus $[9,18,19]$.

The severity of hydrocephalus is usually assessed from clinical signs and symptoms. In very young patients an increase in head circumference usually occurs with only minor symptoms due to the compliance of the immature skull. CT-scanning and intracranial pressure-monitoring have proved to be valuable tools in the assessment of the diagnosis, but many patients still do not show satisfactory outcomes after CSF shunt surgery [20] suggesting an underlying pathophysiological process may not have been addressed by the procedure. The outcome, in terms of possible neurological deficits, may reflect these underlying processes that are not addressed by shunting and thus do not reflect the brain damage that is directly inflicted by hydrocephalus $[4,20,21]$. These deficits may not be rescued or recovered [22] and may be a consequence of poor, or abnormal development of the cerebral cortex $[18,19]$. Thus, although appropriate diagnostics have been developed for hydrocephalus, the potential of 
biological markers to characterise the underlying pathological processes has so far been overlooked.

The composition of the CSF should reflect physiological/biochemical changes happening in the brain parenchyma, and more particularly in the periventricular white matter and sub-ventricular zones lining the ventricles $[23,24]$ where atrophy of the white matter, and to some extent the grey matter and damage to axons were found in various hydrocephalic conditions [3,4,25-28]. In the neonatal period a major phase of gliogenesis occurs in the ventricular and sub-ventricular zones and it is likely that there is a significant effect from hydrocephalus on developing glial cells, but less effect on the postmitotic neurones produced prenatally [29-32]. The aim of this study was to test whether different aetiologies of neonatal hydrocephalus were correlated with different profiles of proteins associated with glial damage in human neonatal hydrocephalus.

\section{Materials and methods Patient samples}

Prior to the study, ethical approval was obtained from the UK NHS REC (ref: 08/H1015/43), Central Manchester NHS Foundation Trust, Alder Hey Children's Hospital, Leeds Teaching Hospitals NHS Trust, The University of Manchester, and The Children's Hospital Lahore. Written informed consent for participation and demographic data including sex, age and ethnicity were obtained from each patient's parents using their home language with verbal explanation where necessary. This study is based on 25 neonates, 16 males and 9 females varying in age from 1 to 44 weeks (Table 1). CSF samples were collected by trained clinical staff either by lumbar puncture from normal infants $(\mathrm{n}=8)$, presenting with mild fever and suspected meningitis but sera negative, or through insertion of catheters into the brain lateral ventricle to drain fluid from infants with hydrocephalus. All CSF samples were sera negative for known infective organisms. Any sera positive samples were excluded from this study as were all samples with obvious blood contamination. The procedures and tests were part of the routine clinical management of the patients and we obtained fluid excess to clinical test requirements. Samples were frozen at $-80^{\circ} \mathrm{C}$ within 30 min of collection. UK samples were transported frozen on dry ice while samples collected from Lahore Children's Hospital, Pakistan, were lyophilised (freeze dried) prior to shipment for analysis in the UK. Lyophilised samples were reconstituted to the original volume using deionised water (Milli-Q) before analysis. For obvious clinical reasons it was not possible to obtain CSF samples from the same site in normal and hydrocephalus infants. Total protein would be higher in lumber CSF but other parameters would be expected to be within normal ranges unless damage, inflammation or infection affected specific regions. Any significant differences between hydrocephalus groups were directly comparable to each other as they were all ventricular samples, but any differences to normal lumbar CSF samples needed to be interpreted with due regard to reported differences between lumbar and ventricular CSF. Obstruction of CSF outflow may also affect composition but one aim of the current study is to determine if CSF composition is indeed altered, by whatever mechanism, in hydrocephalus.

We received limited information concerning each sample so that sub-categorisation based on severity of hydrocephalus, neurological deficits etc. was not possible in this initial study. Thus, we categorised hydrocephalic CSF samples according to age of onset and the cause of hydrocephalus into the following groups: 1 . Fetal-onset or congenital hydrocephalus (FOH) in infants born with classically enlarged heads and associated neurological symptoms $(n=4) ; 2$. Late-onset hydrocephalus $(\mathrm{LOH})$ in infants developing hydrocephalus some days or weeks after birth due to undetermined factors but probably infections $(\mathrm{n}=4)$; 3. Post-haemorrhagic hydrocephalus $(\mathrm{PHH})$ in infants due to an intraventricular or subarachnoid bleed before, during or soon after birth $(n=5) ; 4$. Spina bifida with hydrocephalus $(\mathrm{SB} / \mathrm{HC})$ in infants with a primary neural tube defect $(n=4)$. 5 . Control/normal infants with no neurological condition and sera negative for meningitis $(n=8)$. Sample details are summarised in Table 1.

Table 1 Clinical variables of the normal and hydrocephalic neonates used in the study

\begin{tabular}{|c|c|c|c|c|c|c|c|}
\hline \multicolumn{2}{|c|}{ Patient groups } & \multicolumn{3}{|c|}{ Age (days) } & \multirow{2}{*}{$\begin{array}{c}\text { Sex ratio } \\
\text { (male: female) }\end{array}$} & \multirow{2}{*}{$\begin{array}{l}\text { Site of CSF } \\
\text { collection }\end{array}$} & \multirow{2}{*}{$\begin{array}{c}\text { Source } \\
\text { (UK: Pakistan) }\end{array}$} \\
\hline Groups & $n$ & Age range (days after birth) & Mean & $\overline{\text { SEM }}$ & & & \\
\hline Normal & 8 & $8-92$ & 24.50 & 9.72 & $5: 3$ & Lumber & $0: 8$ \\
\hline $\mathrm{FOH}$ & 4 & $11-30$ & 18.25 & 4.40 & $4: 0$ & Lateral ventricle & $1: 3$ \\
\hline LOH & 4 & $60-300$ & 153.75 & 55.58 & $3: 1$ & Lateral ventricle & $0: 4$ \\
\hline PHH & 5 & $28-132$ & 74.80 & 22.05 & $2: 3$ & Lateral ventricle & $5: 0$ \\
\hline $\mathrm{SB} / \mathrm{HC}$ & 4 & $5-105$ & 41.00 & 22.79 & $2: 2$ & Lateral ventricle & $4: 0$ \\
\hline
\end{tabular}

Number of patients, age (days post-partum), gender, and national distribution of the patients studied grouped by known aetiology. Late onset hydrocephalus $(\mathrm{LOH})$ and spina bifida with hydrocephalus $(\mathrm{SB} / \mathrm{HC})$ infants are somewhat older than the other groups due to the nature of the condition and the time to receiving treatment. All CSF samples were collected from the lateral ventricle except normal samples that were collected by lumbar puncture. Although there is an age range in each group the low number of samples did not allow analysis of age-related changes. FOH: fetal-onset hydrocephalus, PHH: post-haemorrhagic hydrocephalus. 


\section{Western blotting}

All CSF samples were compared through analysis of equal volumes. This was the most meaningful approach since we expected to see changes in total protein as well as in individual components. The specifications for each antibody on the manufacturer's web sites also listed previous publications characterising the antibody as well as its specificity and utility for identifying the target protein. All samples were diluted 1:1 by volume in Laemmli sample buffer (BioRad 161-0737, Hemel Hempstead, UK) containing mercaptoethanol and heated for $7 \mathrm{~min}$ at $95^{\circ} \mathrm{C}$. Protein standards were included in each gel as well as a molecular weight standard (Biorad161-0375). Rat (postnatal day 1 ) astrocyte cell lysates $(5-10 \mu \mathrm{g}$, see below) were used as a positive control for GFAP and vimentin antibodies. The CNPase antibody was well characterised by previous studies of oligodendrocytes and cortical white matter [33,34]. Furthermore, we had previous data from mass spectrometry that CNPase was indeed present in CSF samples [35]. $5 \mu \mathrm{l}$ of each CSF sample were separated together with control proteins and molecular weight markers on a 4-12\% SDS-PAGE gel and transferred to a PVDF membrane using an iBlot system with blotting kits (Invitrogen, Glasgow, UK). The membranes were blocked using 5\% skimmed-milk (Marvel) or 5\% fish skin gelatine (Sigma Poole, UK) in $0.1 \%$ phosphatebuffer solution ( $\mathrm{pH} 7.4$ ) with $0.1 \%$ Tween (Sigma) for 1 hour at room temperature (RT). Primary antibodies were optimised to the following dilutions for 1:4000 $(0.25 \mu \mathrm{g} / \mathrm{ml})$ for rabbit anti-human GFAP (Abcam 7779, Cambridge, UK ), 1:1000 $(0.1 \mu \mathrm{g} / \mathrm{ml})$ for rabbit anti-human Vimentin (Cell Signaling-3932, New England Biolabs, Hitchin, UK), 1:10,000 (0.1 $\mu \mathrm{g} / \mathrm{ml})$ for rabbit anti-human MBP (Thermo Fisher PA1-18324 Lutterworth, UK), 1:1000 $(0.1 \mu \mathrm{g} / \mathrm{ml})$ for rabbit antihuman CNPase (Sigma C9743) were diluted in blocking solution and membranes incubated overnight at $4{ }^{\circ} \mathrm{C}$ without agitation. Membranes were then washed and incubated in a 1:3000 dilution of the secondary antibody, horseradish peroxidise-conjugated anti-rabbit IgG (Cell signalling 7074) in blocking solution for $1 \mathrm{~h}$ at RT with agitation, washed and the signals detected using an enhanced chemiluminescence substrate (Amersham Hyper film ECL, GE Healthcare Little Chalfont, UK) and exposed to film.

\section{Astrocyte cell lysates}

In order to produce astrocyte cell lysates for positive control, 1-day old Sprague-Dawley rat pups (Charles River, Ormiston, Scotland) were killed with an overdose of sodium pentobarbitone given by intraperitoneal injection and then decapitated. 2-4 cerebral hemispheres were dissected under sterile conditions in a laminar flow hood. The cortical hemispheres were placed in ice-cold
Dulbecco's modified medium (DMEM, Invitrogen, Glasgow, UK) and further dissected under a stereo microscope (Leica M3Z). The meninges were removed and the choroid plexus removed from the ventricle. All cleaned hemispheres were then digested with trypsin and gently dissociated through decreasing bore sizes of sterile pipettes. The suspension was centrifuged for $10 \mathrm{~min}$ at $1000 \mathrm{rpm}$, the supernatant discarded and the pellet resuspended in DMEM. After a further centrifugation and resuspension to wash the cells, the pellet was resuspended in $10 \mathrm{ml}$ of DMEM per hemisphere. $10 \mathrm{ml}$ of cell suspension was loaded into poly-D-lysine coated $75 \mathrm{~cm}^{2}$ flasks and placed in a humidified incubator for 7-9 days at $37^{\circ} \mathrm{C}$ with 5\% $\mathrm{CO}_{2}$. After 7-9 day incubation, flasks were sealed tight and shaken on an orbital shaker at $230 \mathrm{rpm}$ for 4 hours at $37^{\circ} \mathrm{C}$ to separate microglial cells from astrocytes. The media was replaced with $10 \mathrm{ml}$ of fresh DMEM and shaken for a further $1 \mathrm{~h}$. The culture was then washed twice with $5 \mathrm{ml}$ of warm PBS with gentle mixing and then the adherent astrocytes lysed using CelLytic M Cell Lysis Reagent (Sigma) for $15 \mathrm{~min}$ at room temperature. Cells were scraped off the flask and the whole media centrifuged to remove cell debris. Protein concentration was measured using a Bradford Assay and 5-10 $\mu$ g total protein loaded on gels as a control for GFAP and vimentin.

\section{Densitometry and statistical analysis}

Films were scanned and the relative density of bands quantified using Image J (Version $1.44 \mathrm{p}, \mathrm{NIH}$ ). Where no bands were obvious a measure of the staining (presumably background) where the band would have been was used for those CSF samples. Data are presented as mean \pm SEM. Results of the experiments were entered into Graphpad Prism V software and the data analysed using one way analysis of variance (ANOVA) and post hoc (Tukey) testing to identify significant differences between groups. The value $p<0.05$ was considered significant. No distribution tests were carried out and the data was assumed to fall within a normal distribution.

\section{Results}

\section{Glial fibrillary acidic protein (GFAP)}

A $53 \mathrm{KDa}$, GFAP-positive protein band present in the CSF from $\mathrm{PHH}$ and $\mathrm{SB} / \mathrm{HC}$ infants was not detected in normal, FOH and LOH samples (Figure 1a). This GFAP-positive protein was significantly increased in $\mathrm{PHH}(P<0.05)$ and showed a non-significant increase in SB/HC CSF when compared with CSF from normal infants (Figure 1b).

\section{Vimentin}

A $55 \mathrm{KDa}$ vimentin-positive protein band was observed in the CSF from two infants with $\mathrm{LOH}$ but was barely detected in normal, FOH, $\mathrm{PHH}$ or $\mathrm{SB} / \mathrm{HC}$ infants (Figure 2a). The presence or absence of the vimentin positive band in 


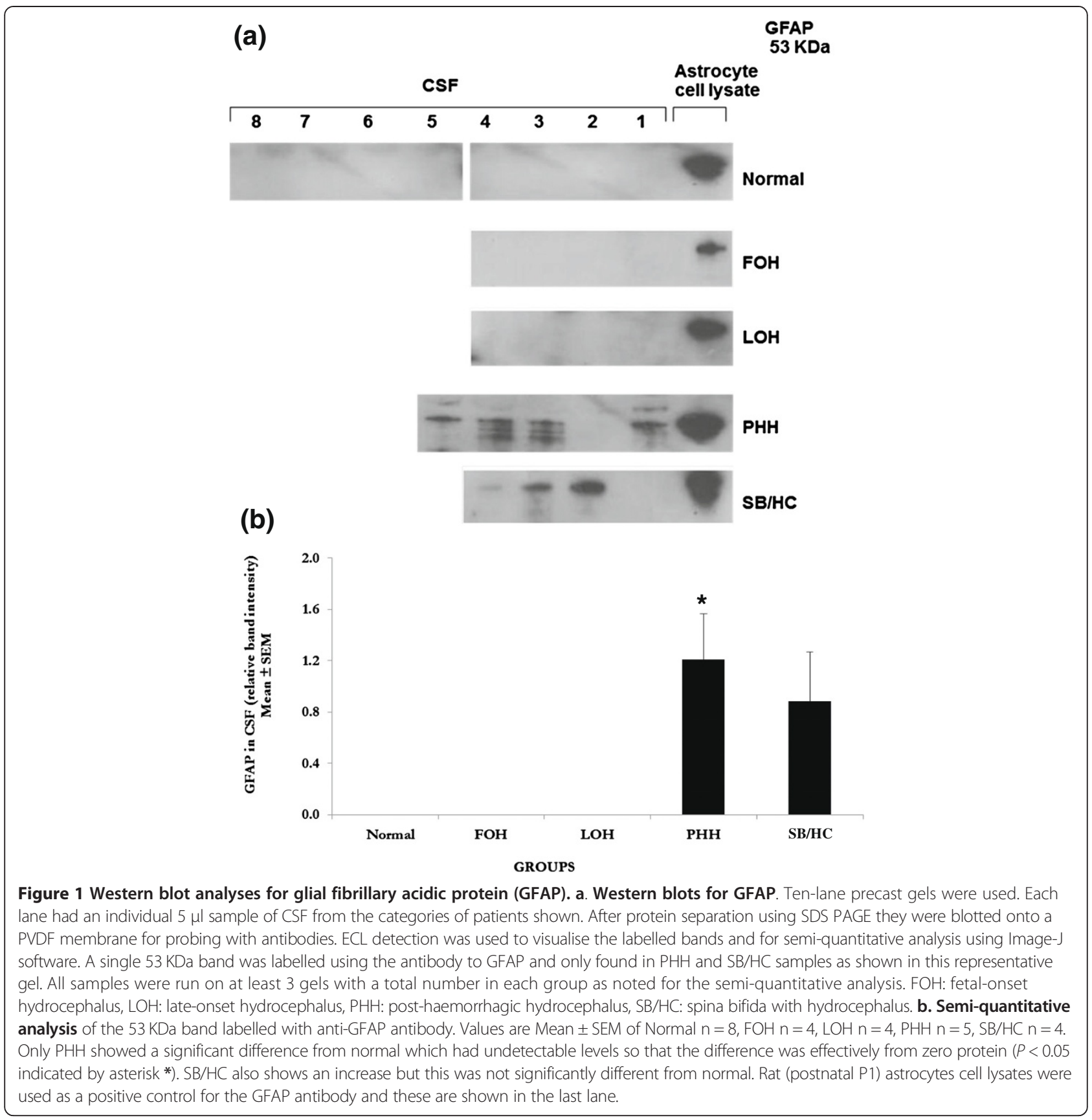

different LOH infants gave a non-significant $(P>0.05)$ statistical test (Figure 2b) against normal. Two of four LOH samples have obviously raised levels of vimentin compared to any other individual tested.

\section{Myelin basic protein (MBP)}

A $40 \mathrm{KDa}$ MBP-positive protein band was observed in the CSF from infants with $\mathrm{PHH}$ and $\mathrm{SB} / \mathrm{HC}$ conditions but was below the detection limit in CSF from normal, $\mathrm{FOH}$ and $\mathrm{LOH}$ infants (Figure 3a). MBP showed a highly significant $(P>0.0001)$ increase in CSF of $\mathrm{PHH}$ and $\mathrm{SB} /$
$\mathrm{HC}$ infants compared to normal. The elevation of MBP in $\mathrm{PHH}$ and $\mathrm{SB} / \mathrm{HC}$ infants showed little variation between different samples analysed.

\section{2', 3'-cyclic nucleotide 3'-phosphodiesterase (CNPase)}

A $45 \mathrm{KDa}$ CNPase-positive protein band was detected in all samples of CSF analysed (Figure 4a). CNPase was significantly lower in $\mathrm{LOH}(P<0.05)$ although one infant had normal levels. CNPase was reduced but without significance in $\mathrm{FOH}$ compared with CSF from normal, PHH and SB/HC infants (Figure $4 \mathrm{~b}$ ). 


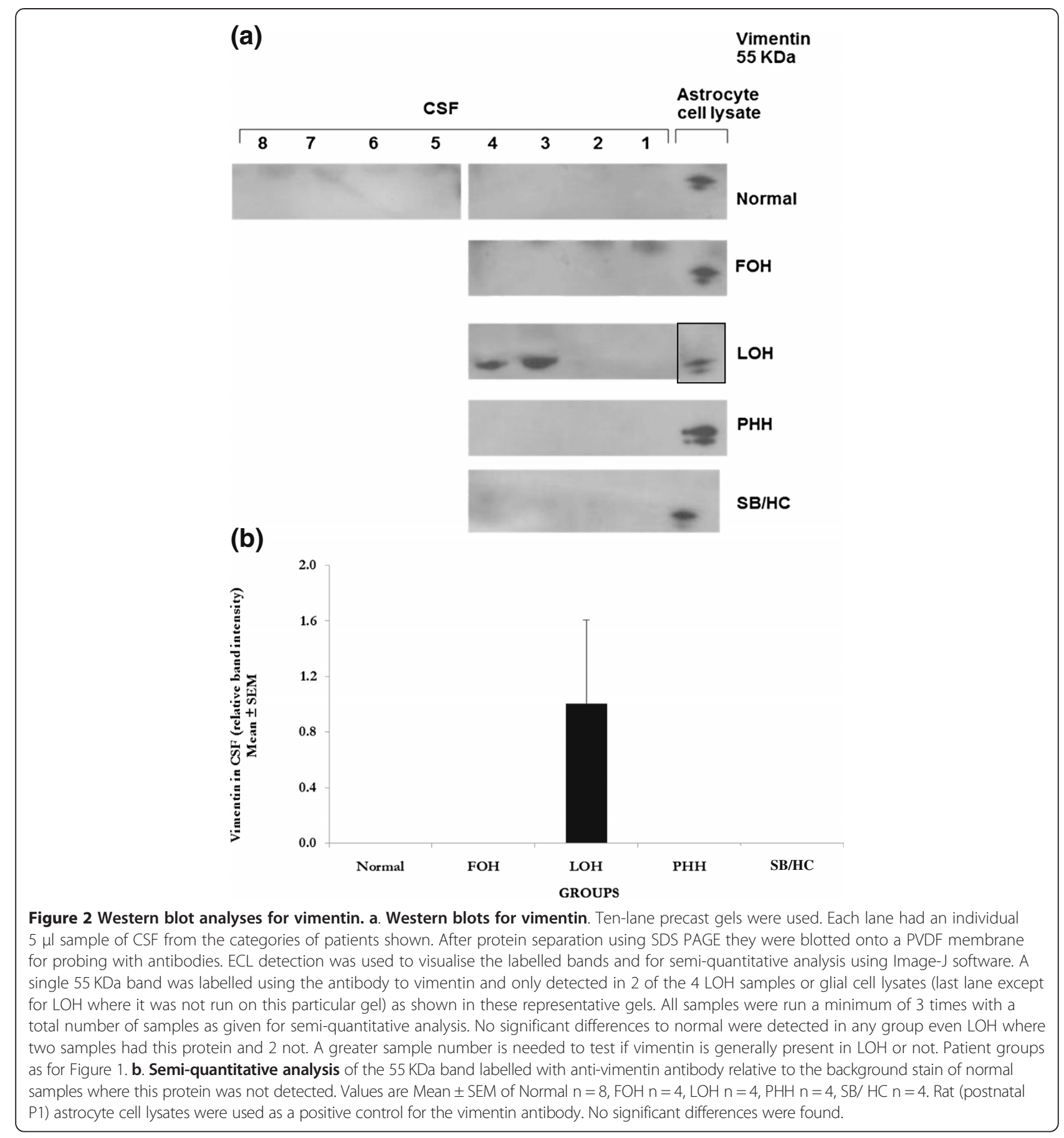

\section{Discussion}

The present study determined CSF levels of GFAP, vimentin, MBP and CNPase in human neonatal hydrocephalus with different aetiologies compared to CSF from neonates with no neurological abnormalities. Although significant differences as well as non-significant indications of differences have been found, the low number of samples available for analysis limited clear conclusions. The study does show that differences are likely to exist and that a larger study is urgently needed. There are clearly sub-categories within each group that show significant changes and so further clinical data may unravel these issues. The proteins we analysed are intermediate filaments found in astrocytes, ependymal cells (GFAP) early glial progenitors and differentiating astrocytes (vimentin) and oligodendrocytes (MBP) and an enzyme associated with the formation of myelin in oligodendrocytes (CNPase). Their presence in CSF is thus thought to indicate cell compromise, 


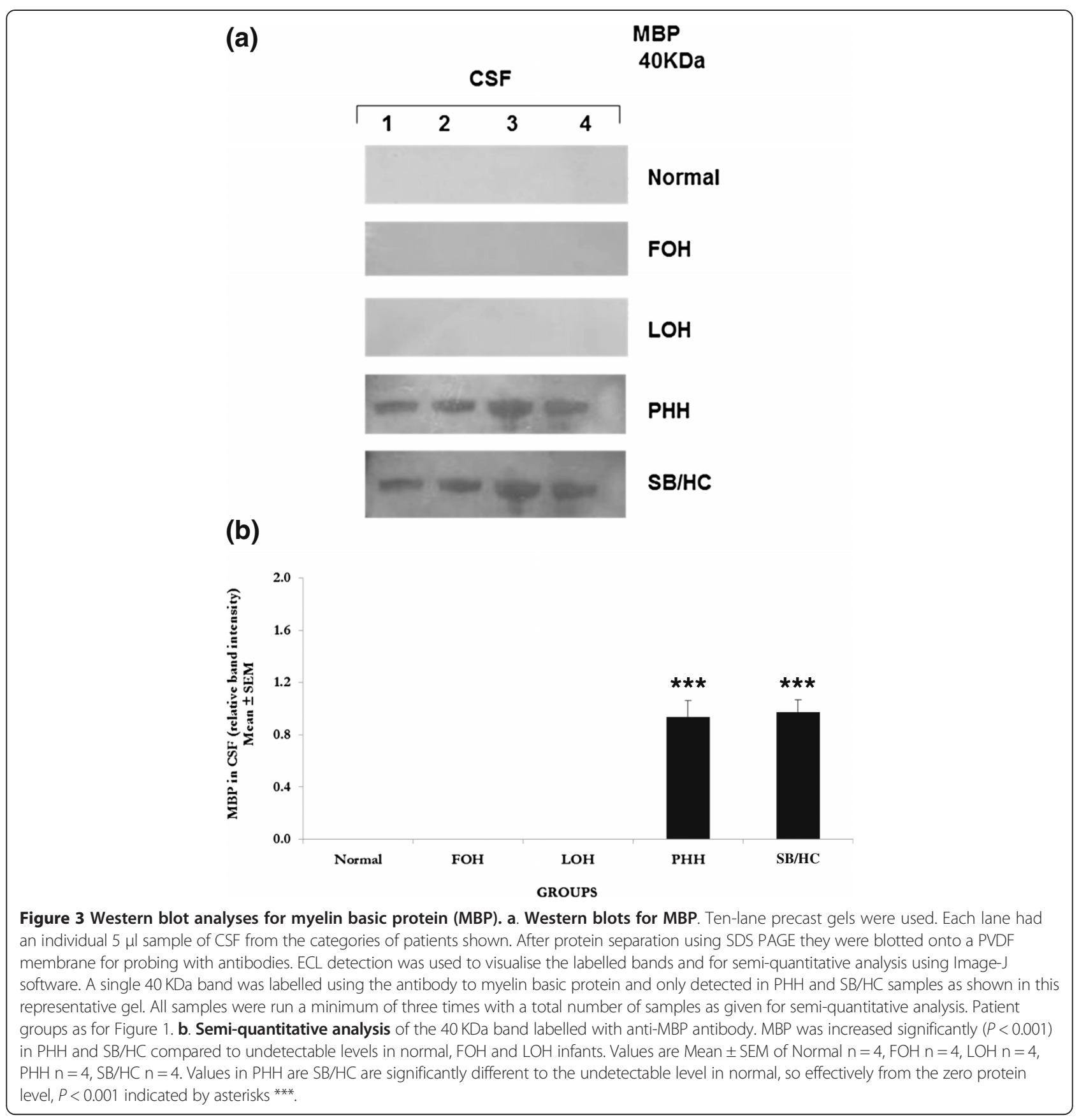

breakdown and release of intracellular components. In this study we found that $\mathrm{FOH}$, the congenital form of hydrocephalus, is not associated with any appearance of cell breakdown products in agreement with previous studies demonstrating absence of cell death [36] and decreased cell proliferation with a cell cycle arrest in the H-Tx rat model of $\mathrm{FOH}[18,19]$. LOH had only vimentin detectable in CSF while $\mathrm{PHH}$ and $\mathrm{SB} / \mathrm{HC}$ had GFAP and MBP but not vimentin in CSF. Interestingly, CNPase has never been described in normal/developmental CSF but we found it in all samples of CSF including those from our non- hydrocephalic control infants. We found it reduced in 3 of 4 samples of LOH compared to other samples and it is interesting to speculate whether the 4th sample might have had a non-infectious cause compared to the normal cause in this category of hydrocephalus. Its presence in all neonatal CSF samples analysed suggests a possible role in the immediate post-natal acceleration of gliogenesis. The source of CSF CNPase must surely be oligodendrocytes and their precursors since no other cell has been shown to express this enzyme. This potential role as a secreted molecule remains to be investigated. It would be very 
(a)
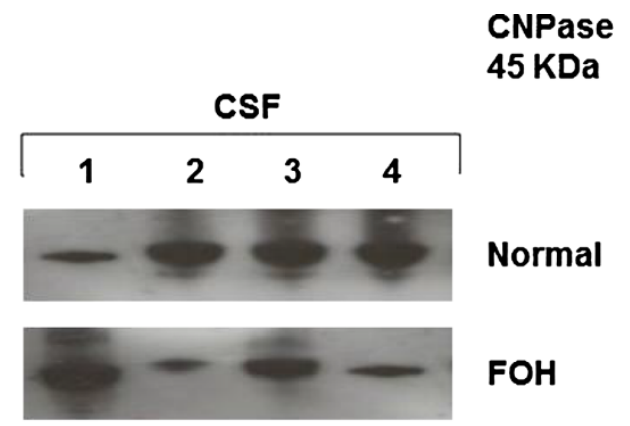

Normal

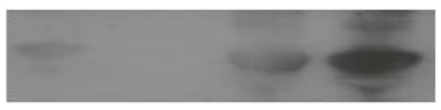

FOH

\section{LOH}

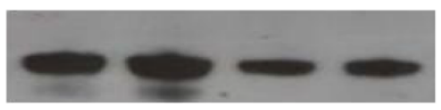

PHH

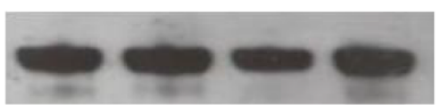

SB/HC

(b)

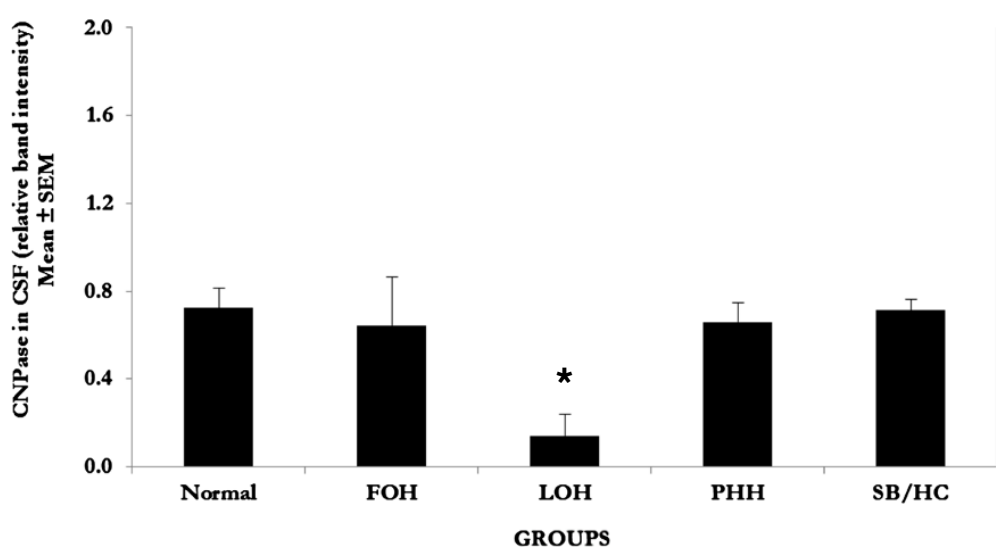

Figure 4 Western blot analyses for 2' , 3'-cyclic nucleotide 3'-phosphodiesterase (CNPase). a. Western blots for CNPase. Ten-lane precast gels were used. Each lane had an individual $5 \mu \mathrm{l}$ sample of CSF from the categories of patients shown. After protein separation using SDS PAGE they were blotted onto a PVDF membrane for probing with antibodies. ECL detection was used to visualise the labelled bands and for semi-quantitative analysis using Image-J software. A single $45 \mathrm{KDa}$ band was labelled using the antibody to CNPase and was detected in all samples as shown in these representative gels. All samples were run a minimum of three times with a total number of samples as shown for semi-quantitative analysis. Patient groups as for Figure 1. b. Semi-quantitative analysis of the $45 \mathrm{KDa}$ band labelled with anti-CNPase antibody shows similar levels of CNPase to that in normal CSF in $\mathrm{FOH}, \mathrm{PHH}$ and $\mathrm{SB} / \mathrm{HC}$ but in the $\mathrm{LOH}$ group where a significant reduction $\left(P<0.05\right.$ indicated by asterisk $\left.{ }^{*}\right)$ was observed compared to normal and other hydrocephalic groups. In the LOH gel 3 of the 4 samples show reduced CNPase compared to normal and one sample not. Increased numbers will provide better resolution of this particular group. Values are Mean \pm SEM of Normal $n=4, F O H n=4, L O H n=4, P H H n=4, S B / H C n=4$.

interesting to test CNPase on the differentiation of oligodendrocytes from cortical stem/progenitor cells in in vitro cell culture as well as to investigate the factors stimulating secretion of this enzyme from oligodendrocytes.

GFAP is an intermediate filament expressed in mature astrocytes [37,38] and immature ependymal cells [39]. Thus the GFAP seen in hydrocephalic CSF may originate from either source as the ependyma is likely to be maturing in the neonatal period. Our findings support those reported for experimental neonatal acquired hydrocephalus $[3,4]$ and also show that congenital and late-onset hydrocephalus, the latter associated with neonatal and postnatal infections, do not present with raised GFAP but that $\mathrm{PHH}$ and $\mathrm{SB} / \mathrm{HC}$ neonates do. GFAP was reported in the CSF of elderly normal pressure hydrocephalus (NPH) patients compared with neurologically healthy agematched controls $[40,41]$ suggesting a common pathophysiology involving astroglial damage in these types of hydrocephalus, but astroglial protection in $\mathrm{FOH}$ and $\mathrm{LOH}$ in the neonate. This protection may not be present in older untreated individuals. The latter point is supported by findings in hydrocephalic $\mathrm{H}-\mathrm{Tx}$ rats in which reactive 
astrogliosis and microgliosis were observed and correlated with the severity of hydrocephalus and increasing age [42]. Moreover, Del Bigio et al. reported significantly increased GFAP levels in hydrocephalic rats which decreased after shunting suggesting an effect of fluid accumulation and/or raised intracranial pressure on these cells [43]. Similar increased GFAP RNA and protein levels were observed in 10-day old kaolininduced hydrocephalic kittens which also decreased after shunting [44]. Ependymal damage is well documented in hydrocephalus as is astrogliosis so it is perhaps not surprising to find GFAP in CSF as a consequence of specific insults. The finding that GFAP is not present in CSF from $\mathrm{FOH}$ and $\mathrm{LOH}$ must therefore indicate protection of these cells from damage in these forms of hydrocephalus. Thus, the current study indicates early-stage pathology differs depending on etiology.

MBP in CSF is an indicator of damage specifically associated with myelination as this protein is only known to be present in oligodendrocytes $[45,46]$. MBP is an important marker to study in hydrocephalus since the degree of pathology and functional neurological deficits are largely associated with lack of, or damage to myelination, e.g. of the corpus callosum and periventricular white matter. We found significantly elevated levels of MBP in the CSF of infants with $\mathrm{PHH}$ and $\mathrm{SB} / \mathrm{HC}$ indicating that demyelination, and/or a failure of myelination is likely to be occurring in these conditions, but not in $\mathrm{FOH}$ or $\mathrm{LOH}$. The intraventricular or subarachnoid bleeding in PHH is likely to contribute directly to brain damage [47] and to the demyelination of the periventricular white matter reported in PHH. Sutton et al., [48] reported the presence of MBP protein in the CSF of hydrocephalic patients with different aetiologies and suggested that active hydrocephalus, associated with progressive ventricular dilatation, would produce periventricular demyelination through mechanical stretching of the brain parenchyma. Increased intracranial pressure has a greater impact on early cognitive development than increased CSF volume, and the negative effect is partially reversible through early ventricular shunting [49] giving improved myelination. The fact that MBP is not detected in $\mathrm{FOH}$ and $\mathrm{LOH}$ again indicates a lack of direct pathology in these specific aetiologies of hydrocephalus and the possibility to prevent loss of myelination through early intervention.

Vimentin is a cytoskeletal intermediate filament involved in maintaining cell integrity in many different cells types including fibroblasts and endothelial cells [50] as well as progenitor cells and early neuronal and glial cells [51-53]. Vimentin is found in neuronal stem and progenitor cells and astrocytes during the early postnatal period and re-expressed in reactive astrocytes in cases of central nervous system injury [54-56]. Microglial cells also express vimentin, specifically after brain damage and/ or activation through local inflammatory mediators [57]. In hydrocephalus vimentin-positive cells increase around disrupted areas of ependyma suggesting that reactive microglia and proliferating immature glial cells are associated with areas of ependymal cell loss [58]. Our data would further suggest that these cells may be compromised by fluid accumulation and raised intracranial pressure. The increased levels of vimentin in the $\mathrm{LOH}$ infants must be a direct consequence of infection affecting the brain but the lack of GFAP in LOH indicates that the source is unlikely to be astroglial and may be microglial, endothelial or leptomeningeal since many patients present with meningitis. This requires further analysis as it indicates a very different pathophysiology in these patients compared to those with other aetiologies of hydrocephalus.

CNPase is a protein accounting for approximately $4 \%$ of myelin protein content and is considered an index of myelin formation $[59,60]$ where the amount of immunoreactive CNPase correlates with the thickness of the myelin sheath in the central nervous system [61,62]. Wu and colleagues [63] reported that they also found CNPase expressed in prenatal and early postnatal microglial cells in rat brain with a gradual decrease with age, essentially undetectable after birth. They suggested that downregulation of CNPase related to the transformation of microglia from the mobile and amoeboid type to the ramified type during development. If confirmed the finding of CNPase in non-myelin producing cells presents a further mystery regarding its functions along with its presence in CSF found in the current study. Absence of CNPase results in serious conditions. CNPase-knockout mice show severe symptoms, including convulsions and ataxia, and most homozygous mice die between 6 and 12 months of age [64]. Decrease in CNPase expression is also observed in chronic schizophrenic patients [65] indicating a possible involvement in the underlying developmental pathology. In kaolin-induced hydrocephalic rats Del Bigio et al. [43] reported decreased CNPase in the corpus callosum/supraventricular white matter, fimbria, medulla, and spinal cord indicating a sensitivity of myelin in these regions to raised intracranial pressure. Furthermore, a reduction in the number of CNPase immunoreactive oligodendrocytes both in the subependymal layer and the cerebral cortex of hydrocephalic rat brains correlated with the severity of the hydrocephalus [66]. CNPase has not been described in neonatal CSF before this study and was an unexpected finding particularly its presence in all neonatal CSF samples tested. LOH had reduced CNPase in CSF compared to normal and other conditions. As CNPase is thought to be involved in oligodendrocyte surface membrane expansion and migration during early stages of axonal ensheathment [67], its presence in CSF may indicate a potential role in global brain myelination 
not previously considered. This requires further study but may prove to be an important tool in promoting myelination in affected brains.

This study has a number of limitations. Firstly, to obtain CSF free of contamination excluded many collected samples so that a much larger study is required to investigate our current findings in more detail. Secondly, it is practically impossible to obtain CSF samples through ventricular catheterisation from healthy neonates due to technical limitations and ethical issues. Similarly, it is unusual to obtain lumbar CSF from hydrocephalic patients. Although some reports indicate that ventricular CSF may be more stable and accurate for measuring pathological changes [68], others contradict this [69]. For our study, all normal samples were taken by lumbar puncture while all hydrocephalic CSF came from lateral ventricles. We assumed that only obstructive hydrocephalus would produce a change in ventricular CSF that was not reflected in lumbar drainage but also acknowledge reported differences in total protein between lumbar and ventricular CSF which we believe would not affect the validity of our findings since we are looking for changes in specific proteins associated with pathology. Of note here is the finding of CNPase in both normal and affected neonatal CSF at equal levels (except in $\mathrm{LOH}$ ) that supports an argument that the measurements are comparable in this study.

Taken together, the findings of this study indicate that different aetiologies leading to hydrocephalus are associated with different pathophysiological mechanisms affecting different cell types, at least in the initial stages where intracranial pressure may not be pathologically raised. The congenital form of hydrocephalus has no detectable pathological markers in CSF but is known to be affected by a physiological block of cell cycle as well as a folate block [18,19]. Differential diagnosis is therefore possible and the potential for more effective treatment of these different conditions may emerge from further research. Further studies are clearly needed and, with more detailed clinical data, e.g., measurements of ventriculomegally and additional radiographical data on brain measures, developmental and neurological signs and symptoms, as well as pre- and post-surgical data, a more robust differential diagnostic is likely to emerge which would feed into research for differential treatment depending on the characterisation of the underlying pathology. Furthermore, we have focused on glial cell effects but additional data on neuronal status is also needed in differentiating between the different aetiologies leading to hydrocephalus.

\section{Conclusions}

This study has demonstrates that different aetiologies leading to neonatal hydrocephalus can likely be differentiated by CSF analysis. This presents an important step in understanding this devastating neurological condition. These results suggest that early-stage changes are associated, not with raised pressure, but with currently unknown physiological changes that affect different cell types in different locations within the hydrocephalic brain. Shunting will only address the common end point of these different aetiologies and is unlikely to address the underlying differences in physiology. It is therefore important to understand these physiological processes in order to prevent irreversible cell damage and lasting neurological deficits.

\section{Abbreviations \\ CNPase: 2', 3'-cyclic nucleotide 3'-phosphodiesteras; CSF: Cerebrospinal fluid; FOH: Fetal-onset hydrocephalus; GFAP: Glial fibrillary Acidic protein; H-Tx: Hydrocephalic Texas rat; LOH: Late onset hydrocephalus; MBP: Myelin basic protein; PHH: Post-haemorrhagic hydrocephalus; SB/HC: Spina bifida with hydrocephalus.}

\section{Competing interests}

The authors declare they have no competing interests.

\section{Authors' contributions}

JAM and IN conceived and designed the study. IN carried out all of the lab work. KAIW, AWR, SV, CM and JRG were involved in providing clinical samples, discussing the study design and data collected. SNC coordinated the work in Pakistan. All authors contributed to various drafts of the manuscript and have read and approved the final version.

\section{Acknowledgements}

Financial support was provided by The Charles Wolfson Charitable Trust (JAM). IN was supported through a British Council INSPIRE grant (SP055) to The University of Manchester, UK and COMSATS Institute for Information Technology, Islamabad, Pakistan that also supported the work carried out in Islamabad and Lahore. We thank Dr Nadeem Malik (Neurosurgeon) and the Neonatology registrars at the Children's Hospital Lahore for CSF collections in Pakistan; Sasha Burn, Dawn Williams, Clare Jennings, Anna Hendrickson, Jennifer Hill for CSF collections in the UK; Professor M. Akhtar, FRS and Dr Naeem of the School of Biological Sciences, University of Punjab, Lahore, for access to laboratory facilities for sample preparation and lyophilisation.

\section{Author details}

${ }^{1}$ Faculty of Life Sciences, The University of Manchester, AV Hill Building, Oxford Road, Manchester M13 9PT, UK. ²Department of Neonatology, The Children's Hospital and Institute of Child Health, Ferozepur Road, Lahore, Pakistan. ${ }^{3}$ Institute of Human Development, Manchester Academic Health Sciences Centre, The University of Manchester, Oxford Road, Manchester M13 9WL, UK. ${ }^{4}$ Neurosurgical Unit, Alder Hey Children's Hospital, Eaton Road, Liverpool L12 2AP, UK. ${ }^{5}$ Department of Neurosurgery, Leeds General Infirmary, Great George Street, Leeds LS1 3EX, UK. 'Department of Biosciences, COMSATS Institute of Information and Technology, Islamabad, Pakistan.

Received: 2 September 2013 Accepted: 14 December 2013 Published: 18 December 2013

\section{References}

1. Zhang J, Williams MA, Rigamonti D: Genetics of human hydrocephalus. J Neurol 2006, 253:1255-1266

2. Pattisapu JV: Etiology and clinical course of hydrocephalus. Neurosurg Clin N Am 2001, 12:651-659. vii.

3. McAllister JP, Chovan P: Neonatal hydrocephalus. Mechanisms and consequences. Neurosurg Clin N Am 1998, 9:73-93.

4. McAllister JP 2nd: Pathophysiology of congenital and neonatal hydrocephalus. Semin Fetal Neonatal Med 2012, 17:285-294. 
5. Vachha B, Adams R: Language sample analysis in children with myelomeningocele and shunted hydrocephalus. Eur J Pediatr Surg 2003, 13(Suppl 1):S36-S37.

6. Hetherington R, Dennis M, Barnes M, Drake J, Gentili F: Functional outcome in young adults with spina bifida and hydrocephalus. Childs Nervous System 2006, 22:117-124.

7. Milhorat TH: Hydrocephalus and the Cerebrospinal Fluid. Baltimore: Williams and Wilkins Co; 1972

8. Milhorat TH, Davis DA, Hammock MK: Localization of ouabin-sensitive Na-K ATPase in frog, rabbit and rat choroid plexus. Brain Res 1975, 99:170-174.

9. Cains S, Shepherd A, Nabiuni M, Owen-Lynch PJ, Miyan J: Addressing a folate imbalance in fetal cerebrospinal fluid can decrease the incidence of congenital hydrocephalus. J Neuropathol Exp Neurol 2009, 68:404-416.

10. Gato A, Desmond ME: Why the embryo still matters: CSF and the neuroepithelium as interdependent regulators of embryonic brain growth, morphogenesis and histiogenesis. Dev Biol 2009, 327:263-272.

11. Lehtinen MK, Walsh CA: Neurogenesis at the brain-cerebrospinal fluid interface. Annu Rev Cell Dev Biol 2011, 27:653-679.

12. Lehtinen MK, Zappaterra MW, Chen X, Yang YJ, Hill AD, Lun M, Maynard T, Gonzalez D, Kim S, Ye P, et al: The cerebrospinal fluid provides a proliferative niche for neural progenitor cells. Neuron 2011, 69:893-905.

13. Zappaterra MW, Lehtinen MK: The cerebrospinal fluid: regulator of neurogenesis, behavior, and beyond. Cell Mol Life Sci 2012, 69:2863-2878.

14. Miyan JA, Zendah M, Mashayekhi F, Owen-Lynch PJ: Cerebrospinal fluid supports viability and proliferation of cortical cells in vitro, mirroring in vivo development. Cerebrospinal Fluid Res 2006, 3:2.

15. Nabiuni M, Rasouli J, Parivar K, Kochesfehani HM, Irian S, Miyan JA: In vitro effects of fetal rat cerebrospinal fluid on viability and neuronal differentiation of PC12 cells. Fluids Barriers CNS 2012, 9:8

16. Schutzer SE, LiU T, Natelson BH, Angel TE, Schepmoes AA, Purvine SO, Hixson KK, Lipton MS, Camp DG, Coyle PK, et al: Establishing the proteome of normal human cerebrospinal fluid. PLoS One 2010, 5:e10980.

17. Morales DM, Townsend RR, Malone JP, Ewersmann CA, Macy EM, Inder TE, Limbrick DD Jr: Alterations in protein regulators of neurodevelopment in the cerebrospinal fluid of infants with posthemorrhagic hydrocephalus of prematurity. Mol Cell Proteomics 2012, 11:M111 011973.

18. Owen-Lynch PJ, Draper CE, Mashayekhi F, Bannister CM, Miyan JA: Defective cell cycle control underlies abnormal cortical development in the hydrocephalic Texas rat. BRAIN 2003, 126:623-631.

19. Mashayekhi F, Draper CE, Bannister CM, Pourghasem M, Owen-Lynch PJ, Miyan JA: Deficient cortical development in the hydrocephalic Texas (H-Tx) rat: a role for CSF. BRAIN 2002, 125:1859-1874.

20. Hale PM, Mcallister JP, Katz SD, Wright LC, Lovely TJ, Miller DW, Wolfson BJ, Salotto AG, Shroff DV: Improvement of cortical morphology in infantile hydrocephalic animals after ventriculoperitoneal shunt placement. Neurosurgery 1992, 31:1085-1096.

21. Mori K, Shimada J, Kurisaka M, Sato K, Watanabe K: Classification of hydrocephalus and outcome of treatment. Brain Dev 1995, 17:338-348.

22. Hawkins D, Bowers TM, Bannister CM, Miyan JA: The functional outcome of shunting H-Tx rat pups at different ages. Eur J Pediatr Surg 1997, 7(Suppl 1):31-34

23. McKeating EG, Andrews PJ, Tocher Jl, Menon DK: The intensive care of severe head injury: a survey of non-neurosurgical centres in the United Kingdom. Br J Neurosurg 1998, 12:7-14.

24. Wikkelso C, Blomstrand C: Cerebrospinal fluid proteins and cells in normal-pressure hydrocephalus. J Neurol 1982, 228:171-180.

25. Del Bigio MR: Neuropathological changes caused by hydrocephalus. Acta Neuropathol 1993, 85:573-585.

26. Del Bigio MR, Bruni JE, Vriend JP: Monoamine neurotransmitters and their metabolites in the mature rabbit brain following induction of hydrocephalus. Neurochem Res 1998, 23:1379-1386.

27. Del Bigio MR, da Silva MC, Drake JM, Tuor Ul: Acute and chronic cerebral white matter damage in neonatal hydrocephalus. Can J Neurol Sci 1994, 21:299-305.

28. Harris NG, Jones HC, Patel S: Ventricle shunting in young $\mathrm{H}$-Tx rats with inherited congenital hydrocephalus: a quantitative histological study of cortical grey matter. Childs Nerv Syst 1994, 10:293-301. discussion 301.

29. Kondziella D, Qu H, Ludemann W, Brinker T, Sletvold O, Sonnewald U: Astrocyte metabolism is disturbed in the early development of experimental hydrocephalus. J Neurochem 2003, 85:274-281.
30. Murray K, Noble M: In vitro studies on the comparative sensitivities of cells of the central nervous system to diphtheria toxin. J Neurol Sci 1985, 70:283-293

31. Khan $\mathrm{OH}$, Enno $\mathrm{TL}$, Del Bigio MR: Brain damage in neonatal rats following kaolin induction of hydrocephalus. Exp Neurol 2006, 200:311-320.

32. Del Bigio MR, Zhang YW: Cell death, axonal damage, and cell birth in the immature rat brain following induction of hydrocephalus. Exp Neurol 1998, 154:157-169.

33. Ding YX, Wei LC, Liu YH, Duan L, Jiao XY, Xia Y, Chen LW: Midbrain neural stem cells show unique cell survival, neuronal commitment and neurotrophic properties with therapeutic potential for parkinson's disease. J Alzheimers Dis Res 2012, S10:001. doi:10.4172/2161-0460.

34. Stephenson DT, O'Neill SM, Narayan S, Tiwari A, Arnold E, Samaroo HD Du F, Ring RH, Campbell B, Pletcher $M$, et al: Histopathologic characterization of the BTBR mouse model of autistic-like behavior reveals selective changes in neurodevelopmental proteins and adult hippocampal neurogenesis. Mol Autism 2011, 2:7.

35. Nabiuni M: Analysis of protein content of cerebrospinal fluid in developing hydrocephalic texas rat, PhD Thesis. The University of Manchester, Faculty of Life Sciences; 2006.

36. Miyan JA, Khan MI, Kawarada Y, Sugiyama T, Bannister CM: Cell death in the brain of the HTx rat. Eur J Pediatr Surg 1998, 8(Suppl 1):43-48.

37. Bartosik-Psujek $H$, Stelmasiak Z: Biochemical markers of damage of the central nervous system in multiple sclerosis. Ann Univ Mariae Curie Sklodowska Med 2001, 56:389-392.

38. Malmestrom C, Haghighi S, Rosengren L, Andersen O, Lycke J: Neurofilament light protein and glial fibrillary acidic protein as biological markers in MS. Neurology 2003, 61:1720-1725.

39. Roessmann U, Velasco ME, Sindely SD, Gambetti P: Glial fibrillary acidic protein (GFAP) in ependymal cells during development. An immunocytochemical study. Brain Res 1980, 200:13-21.

40. Albrechtsen $M$, Sorensen PS, Gjerris F, Bock E: High cerebrospinal fluid concentration of glial fibrillary acidic protein (GFAP) in patients with normal pressure hydrocephalus. J Neurol Sci 1985, 70:269-274.

41. Tullberg M, Rosengren L, Blomsterwall E, Karlsson JE, Wikkelso C: CSF neurofilament and glial fibrillary acidic protein in normal pressure hydrocephalus. Neurology 1998, 50:1122-1127.

42. Miller JM, McAllister JP 2nd: Reduction of astrogliosis and microgliosis by cerebrospinal fluid shunting in experimental hydrocephalus. Cerebrospinal Fluid Res 2007, 4:5

43. Del Bigio MR, Kanfer JN, Zhang YW: Myelination delay in the cerebral white matter of immature rats with kaolin-induced hydrocephalus is reversible. J Neuropathol Exp Neurol 1997, 56:1053-1066.

44. Eskandari R, Harris CA, McAllister JP 2nd: Reactive astrocytosis in feline neonatal hydrocephalus: acute, chronic, and shunt-induced changes. Childs Nerv Syst 2011, 27:2067-2076.

45. Levin SD, Hoyle NR, Brown JK, Thomas DG: Cerebrospinal fluid myelin basic protein immunoreactivity as an indicator of brain damage in children. Dev Med Child Neurol 1985, 27:807-813.

46. Miller A, Glass-Marmor L, Abraham M, Grossman I, Shapiro S, Galboiz Y: Bio-markers of disease activity and response to therapy in multiple sclerosis. Clin Neurol Neurosurg 2004, 106:249-254.

47. Yung YC, Mutoh T, Lin ME, Noguchi K, Rivera RR, Choi JW, Kingsbury MA, Chun J: Lysophosphatidic acid signaling may initiate fetal hydrocephalus. Sci Transl Med 2011, 3:99ra87.

48. Sutton LN, Wood JH, Brooks BR, Barrer SJ, Kline M, Cohen SR: Cerebrospinal fluid myelin basic protein in hydrocephalus. J Neurosurg 1983, 59:467-470.

49. Hanlo PW, Gooskens RJ, van Schooneveld M, Tulleken CA, van der Knaap MS, Faber JA, Willemse J: The effect of intracranial pressure on myelination and the relationship with neurodevelopment in infantile hydrocephalus. Dev Med Child Neurol 1997, 39:286-291.

50. Franke WW, Schmid E, Osborn M, Weber K: Different intermediate-sized filaments distinguished by immunofluorescence microscopy. Proc Natl Acad Sci U S A 1978, 75:5034-5038.

51. Kamei $Y$, Inagaki N, Nishizawa M, Tsutsumi O, Taketani Y, Inagaki M: Visualization of mitotic radial glial lineage cells in the developing rat brain by Cdc2 kinase-phosphorylated vimentin. Glia 1998, 23:191-199.

52. Kalman M, Szekely AD, Csillag A: Distribution of glial fibrillary acidic protein and vimentin-immunopositive elements in the developing chicken brain from hatch to adulthood. Anat Embryol (Berl) 1998, 198:213-235. 
53. Sancho-Tello M, Valles S, Montoliu C, Renau-Piqueras J, Guerri C: Developmental pattern of GFAP and vimentin gene expression in rat brain and in radial glial cultures. Glia 1995, 15:157-166.

54. Mucke L, Eddleston M: Astrocytes in infectious and immune-mediated diseases of the central nervous system. FASEB J 1993, 7:1226-1232.

55. Eddleston M, de la Torre JC, Oldstone MB, Loskutoff DJ, Edgington TS, Mackman N: Astrocytes are the primary source of tissue factor in the murine central nervous system. A role for astrocytes in cerebral hemostasis. J Clin Invest 1993, 92:349-358.

56. Eddleston M, Mucke L: Molecular profile of reactive astrocytes-implications for their role in neurologic disease. Neuroscience 1993, 54:15-36.

57. Graeber MB, Streit WJ, Kreutzberg GW: The microglial cytoskeleton: vimentin is localized within activated cells in situ. J Neurocytol 1988, 17:573-580

58. Takano T, Rutka JT, Becker LE: Overexpression of nestin and vimentin in ependymal cells in hydrocephalus. Acta Neuropathol 1996, 92:90-97.

59. Reinikainen KJ, Pitkanen A, Riekkinen PJ: 2',3'-cyclic nucleotide-3'phosphodiesterase activity as an index of myelin in the post-mortem brains of patients with Alzheimer's disease. Neurosci Lett 1989, 106:229-232.

60. Vogel US, Thompson RJ: Molecular structure, localization, and possible functions of the myelin-associated enzyme $2^{\prime}, 3^{\prime}$-cyclic nucleotide 3'-phosphodiesterase. J Neurochem 1988, 50:1667-1677.

61. Braun PE, Sandillon F, Edwards A, Matthieu JM, Privat A: Immunocytochemical localization by electron microscopy of $2^{\prime} 3^{\prime}$-cyclic nucleotide 3 '-phosphodiesterase in developing oligodendrocytes of normal and mutant brain. J Neurosci 1988, 8:3057-3066.

62. Trapp BD, Bernier L, Andrews SB, Colman DR: Cellular and subcellular distribution of 2',3'-cyclic nucleotide 3'-phosphodiesterase and its mRNA in the rat central nervous system. J Neurochem 1988, 51:859-868.

63. Wu CY, Lu J, Cao Q, Guo CH, Gao Q, Ling EA: Expression of 2',3'-cyclic nucleotide $3^{\prime}$-phosphodiesterase in the amoeboid microglial cells in the developing rat brain. Neuroscience 2006, 142:333-341.

64. Lappe-Siefke C, Goebbels S, Gravel M, Nicksch E, Lee J, Braun PE, Griffiths IR, Nave KA: Disruption of Cnp1 uncouples oligodendroglial functions in axonal support and myelination. Nat Genet 2003, 33:366-374.

65. Hakak Y, Walker JR, Li C, Wong WH, Davis KL, Buxbaum JD, Haroutunian V, Fienberg AA: Genome-wide expression analysis reveals dysregulation of myelination-related genes in chronic schizophrenia. Proc Natl Acad Sci U S A 2001, 98:4746-4751.

66. Olopade FE, Shokunbi MT, Siren AL: The relationship between ventricular dilatation, neuropathological and neurobehavioural changes in hydrocephalic rats. Fluids Barriers CNS 2012, 9:19.

67. Yin X, Peterson J, Gravel M, Braun PE, Trapp BD: CNP overexpression induces aberrant oligodendrocyte membranes and inhibits MBP accumulation and myelin compaction. J Neurosci Res 1997, 50:238-247.

68. Talab R, Valis M, Rehak S, Krejsek J: Abnormalities of tau-protein and beta-amyloid in brain ventricle cerebrospinal fluid. Neuro Endocrinol Lett 2009, 30:647-651.

69. Moghekar A, Goh J, Li M, Albert M, O'Brien RJ: Cerebrospinal fluid Abeta and tau level fluctuation in an older clinical cohort. Arch Neurol 2012, 69:246-250

doi:10.1186/2045-8118-10-34

Cite this article as: Naureen et al:: Fingerprint changes in CSF composition associated with different aetiologies in human neonatal hydrocephalus: glial proteins associated with cell damage and loss. Fluids and Barriers of the CNS 2013 10:34.

\section{Submit your next manuscript to BioMed Central and take full advantage of:}

- Convenient online submission

- Thorough peer review

- No space constraints or color figure charges

- Immediate publication on acceptance

- Inclusion in PubMed, CAS, Scopus and Google Scholar

- Research which is freely available for redistribution 